\title{
Contribution of Knowledge Management Activities to Organisational Business Performance
}

\begin{abstract}
Purpose - Within construction industry there is a growing awareness of the need for linking knowledge management (KM) to business strategy, organisational objectives, and existing performance measures. This study was undertaken within the context of construction organisations, and attempts to provide the empirical evidence about the relationships between $\mathrm{KM}$ activities and organisational business performance.
\end{abstract}

Design/ methodology/ approach - A questionnaire survey was administered to a sample of construction contractors operating in Hong Kong to investigate the opinions of construction professionals regarding the intensity of KM activities and business performance within their organisations. In parallel to the survey, semi-structured interviews were undertaken to provide qualitative insights that helped to clarify and deepen understanding of the KM process within the context of the research target.

Findings - The investigation shows that knowledge utilisation is the strongest contributor to general business performance. In addition, the impact of $\mathrm{KM}$ activities on the lagging performance indicators of the BSC, such as 'financial performance', is in an indirect manner, and through the leading indicators such as performance from 'internal process' as well as 'learning and growth' perspectives.

Originality/ value - The study empirically established the linkage between intensity of KM activities and business performance, and demonstrated that KM strategies need to be explicitly formulated and measured according to organisational business objectives.

Keywords - knowledge management, performance measurement, organisational objective, the Balanced Scorecard, construction organisations

Paper type - Research paper 


\section{Introduction}

Construction activities can be highly knowledge-intensive. Specialised expert knowledge and problemsolving know-how are the real products of knowledge-intensive services, such as design, architecture and surveying (Hari et al., 2005). The organisations within the construction industry have been managing knowledge informally for years (Hari et al., 2005). The increasing need to manage the challenges facing the industry in today's knowledge economy demands a structured approach to knowledge management (KM), and alignment of KM with business strategy and existing performance measures (Robinson et al., 2005). It has been suggested that, within construction context, performance of KM can be better evaluated by a systematic framework developed based on the strategic map of the Balanced Scorecard (BSC), since this framework links the indicators of KM to organisational business objectives, and convert the investment of the resources and efforts to the output (Yu and Chang, 2005).

Despite a substantial body of KM literature, it is still widely recognised that the empirical validation of the relationships between KM activities and organisational business performance is limited. In order to provide empirical evidence for the theoretical claim that $\mathrm{KM}$ is capable of leveraging intellectual assets to realise desired organisational objectives (Cavaleri, 2004; Sveiby, 1997), and establish the link between KM activities and business performance measures, this study empirically identify the relationships between KM activities and organisational business performance measured from the four (4) strategic perspectives of the BSC (Kaplan and Norton, 1996), within the context of construction organisations.

\section{KM from a strategic perspective}

Organisational knowledge can be viewed as a valuable strategic asset with potential for influencing future actions (Alavi and Leidner, 2001). Accordingly, organisational knowledge management (KM) predominantly focuses on knowledge-related activities to facilitate knowledge creation, capture, transformation and use, with the ultimate aim of leveraging organisations' intellectual capital to achieve organisational objectives (Cavaleri, 2004; Sveiby, 1997). From a strategic perspective, KM activities within business organisations interact with each other to form a process that receives input from its context (i.e. the external and internal business environments), and produces valid knowledge that can be justified by desired business performance (Diakoulakis et al., 2004). Within the context of construction organisations, KM process starts with recognising and identifying the knowledge to be captured, followed by examining the needs of and implement tools (techniques and technologies) for acquiring the knowledge; then captured knowledge is subsequently filtered, refined, analysed, stored and shared; once 
the knowledge is disseminated, new knowledge is created through knowledge utilisation in the new production process; and based on the updated organisational knowledge new circle of KM process begins (Hari et al., 2005). KM activities in this process can be strategically classified into four key dimensions: i.e. responsiveness to knowledge within the business environment; knowledge acquisition; knowledge dissemination and knowledge utilisation (McCann and Buckner, 2004). The interactions between these KM activities have been empirically established (Chen and Mohamed, 2007).

\section{Linking KM with organisational performance through measurement}

If $\mathrm{KM}$, as it claims, focuses on building the successful link between knowledge and performance (Kalling, 2003), then it is logical to assume KM activities will help to produce valid organisational knowledge, which is justified by its ability to perform (Mouritsen, 2004). A performance measurement framework is therefore required to determine how successful $\mathrm{KM}$ activities have been in attaining organisational objectives (Chen and Chen, 2006). A recent investigation shows that construction organisations have favoured the BSC and the European Foundation for Quality Management Excellence Model (EFQM Excellence Model) for internal management (Bassioni et al., 2004). The EFQM Excellence Model is designed as an audit tool to facilitate excellent quality management, hence focuses on auditing what has already happened, rather than addressing strategic issues such as formulation and evaluation of strategy (Andersen et al., 2000; Wongrassamee et al., 2003). Whilst the BSC has been recommended as a suitable measurement framework for strategic management purposes for construction organisations (Bassioni et al., 2005; Kagioglou et al., 2001), due to its intention of creating insights into the value drivers, which are the vital intangible assets that determine future success and form the basis for formulating resource-based strategies (Andriessen, 2004).

Through measuring organisational business performance across four balanced perspectives (financial, customer, internal business processes, and learning), the BSC not only retains an emphasis on achieving financial objectives, but also includes: 1) the performance drivers of these financial objectives (e.g. 'business processes' and 'learning'); and more importantly, 2) hypotheses about the causal relationship between non-financial assets and performance (Kaplan and Norton, 1996: 21, 30-31). The causality between the four perspectives of the BSC provides a "strategic map" to establish a cause-and-effect logic mapping between performance measures and strategy outcomes (Wongrassamee et al., 2003). The BSC has been used to evaluate the KM performance from internal performance measurement perspective and focusing on process efficiency and goal achievement efficiency (Chen and Chen, 2006). It has also been 
suggested that, within construction context, performance of $\mathrm{KM}$ activities can be better evaluated by a systematic framework developed based on the strategic map of the BSC (Yu and Chang, 2005).

\section{Theoretical study framework}

A theoretical framework is proposed herein to empirically investigate relationships between the activities and performance output of the KM process in the single firm environment of construction contracting organisations. The framework has the following four theoretical constructs representing key strategic KM activities:

1. KR 'Responsiveness to knowledge': knowledge activities of responding to the various types of knowledge an organisation has access to, in its external as well as internal business environments (Darroch, 2003);

2. KA 'Knowledge acquisition': knowledge activities of seeking and acquiring knowledge from the external business environment and creating new knowledge based on existing knowledge (Darroch, 2003; Gold et al., 2001);

3. KD 'Knowledge dissemination': creation and maintenance of structures, systems and processes for sharing knowledge across different levels of the organisation, and for retaining knowledge within the organisation (McCann and Buckner, 2004); and

4. KU 'Knowledge utilisation': knowledge activities towards the utilisation of knowledge (Gold et al., 2001).

Recent empirical studies (Darroch, 2003; Gold et al., 2001) provide basic measurable items for operationally defining the above four KM constructs. Whilst many of these items were adopted in this study, others had been modified in view of the findings of relevant construction-specific studies (Egbu et al., 2003; Kululanga et al., 1999; Kululanga et al., 2002). The process of constructs operationalisation was completed through a pilot questionnaire survey administered to a sample of 43 managerial and professional staff members from contracting organisations operating within Hong Kong. Based on this pilot study, items with very low implementation levels were excluded leaving a total of 41 items to operationally define the above four constructs.

In addition to the four KM constructs, one more construct was developed to model organisational business performance. To operationalise this 'Business Performance' (BP) construct, the original measurement themes of the BSC (Kaplan and Norton, 1996) were used as guidelines, and a total of 21 
items were adopted from recent empirical and case studies (Droge et al., 2003; Gold et al., 2001; Jashapara, 2003; Nesan, 2004) to represent business performance from the following four different perspectives:

1. PF 'financial perspective' measures economic consequences of actions already taken;

2. PC 'customer perspective' measures the organisation's performance within the target market segments;

3. PP 'business process perspective' measures the internal-business-process derived from the explicit strategies the organisation has developed to meet shareholder and target clients' expectations; and

4. PL 'learning perspective' measures the infrastructure (people, system, and organisational procedures) the organisation has built to create long-term growth and improvement.

The theoretical study framework, comprising the above five constructs, hypothesises that:

$\mathrm{H} 1$ : The $\mathrm{KM}$ and $\mathrm{BP}$ construct comprises reliable and valid instruments for measuring organisational business performance;

$\mathrm{H} 2$ : Intensity of $\mathrm{KM}$ activities, within an organisation, is positively associated with the level of its business performance;

H3: Intensity of KM activities could be used to predict, and to explain, the level of business performance measured from the different BSC perspectives;

H4: The level of business performance measured from the different BSC perspectives is affected, to a varying degree, by the intensity of KM activities; and

H5: The level of business performance measured from one perspective of the BSC predicts that measured from another perspective.

The graphical description of the relationships proposed by the theoretical framework is illustrated in Figure 1. This study is exploratory in nature, and aims to validate the effectiveness of KM through identifying if, within the construction organisations, the perceived intensity level of KM activities is positively related to the perceived level of business performance. 


\section{Research methodology}

A cross-sectional study design was adopted to provide a snapshot of KM activities being executed and the corresponding business performance. Data were gathered via a mail questionnaire survey targeting a representative sample of construction contractors operating in Hong Kong. The questionnaire was designed to elicit respondents' opinions on the intensity level of KM activities being executed within their respective organisations, and their organisational business performance during the financial year prior to the survey. Considering Five-point scale supports the research method chosen by this study (Byrne, 2001: 72; Neuman, 2003: 207), and had been adopted by previous quantitative KM studies (Darroch, 2003; Moffett et al., 2003), this type of scale was used to measure the operationally-defined items of the five constructs. The questionnaire was pre-tested via a pilot study engaging 10 managers representing different contractors operating in Hong Kong. The data collection process began after the questionnaire had been finalised, based on the pre-test feedback.

To select sample candidates, two trade directories were referred to, i.e. the "List of Approved Contractors for Public Works" (ETWB, 2005) published through the website of the Environment, Transport and Works Bureau of the Government of the Hong Kong Special Administrative Region; and the "Members List” (HKCA, 2005) of the Hong Kong Construction Association, whose members represent local and overseas contractors operating in Hong Kong. Large- and medium-sized contractors within Hong Kong represent the theoretical population, because they provide a relatively better environment for KM compared with small contractors (Ng, 2003; Robinson et al., 2005).

In order to provide more insights into the phenomenon under investigation, the open-ended questions designed in the questionnaire request respondents to describe KM activities that they perceive as positive contributors to their organisational business performance. A total of 50 respondents, from 28 different contracting organisations, provided an array of answers to this request. Also, in parallel to the survey, a total of 15 semi-structured interviews were undertaken with managerial staff members representing 12 large- to medium-sized contractors operating in Hong Kong. The interviewees include one chairman, one managing director, six directors, two regional branch managers, three project managers and two department managers. The interviewees were asked to describe KM activities and related systems being implemented within their organisations, to indicate $\mathrm{KM}$ activities that were most important to their business, and to highlight the contribution of these activities to the overall business performance. 


\section{Survey responses}

Gathered data were analysed using the Statistical Package for Social Science SPSS version 12.0. A total of 149 usable responses were received from 99 organisations representing about $38 \%$ of the research population. No more than five feedback questionnaires were chosen from each organisation to avoid bias in the data. Responses were considered a good representation of the opinions of the population, since the majority of the respondents are at peak of their career, knowledgeable about KM activities within their own organisations, aware of local market dynamics and forces, and representatives of organisations with diverse annual turnover. The detailed demographical information about the respondents is summarised in Table I.

\section{$=====$ Take in Table $\mathrm{I}====$}

\section{Measurement scale development}

Six cases (containing missing values) were deleted from the data file keeping 143 usable responses. Data screening techniques were applied to all variables to assess their distribution to ensure that normality and linearity are reasonably upheld (Tabachinick and Fidell, 2001). Factor analysis (VARIMAX method) was adopted for identifying the structure among the set of measurement variables for each construct in the theoretical framework, and also for data reduction. The 143 cases exceeds the minimum requirement for factor analysis (Hair et al., 1998: 98). Checks were undertaken to ensure factorability is upheld for all factor analysis scenarios (Coakes, 2005). Since the constructs were conceptually defined based on a combination of the literature review, previous empirical studies, and the pilot study, the scales are also considered to have face validity (Hair et al., 1998:117). The reliability coefficients of all scales are above the low limit of 0.70 , indicating satisfactory internal consistency. The foregoing confirms that the developed constructs comprise reliable and valid items for operationally defining the KM and BP constructs; hence hypothesis H1 is supported.

Based on their eigenvalues (greater than 1) and inspections of the screeplots, the analyses identified nine factors for KM constructs, where the constructs of KR 'responsiveness to knowledge'; KA 'knowledge acquisition’; KD ‘knowledge dissemination’ and KU 'knowledge utilisation’ are represented with two, four, two and a single factors, respectively (labelled KM1 through to KM9). The BP construct was identified with four factors, which were in line with the BSC perspectives. Accordingly, these factors were labelled PF 'performance from the financial perspective', PC 'performance from the customer 
perspective', PP 'performance from the business process perspective' and PL 'performance from the learning perspective'. The results of the five factor analysis scenarios (for $\mathrm{KR}, \mathrm{KA}, \mathrm{KD}, \mathrm{KU}, \mathrm{BP}$ ) are summarised in Table II and III.

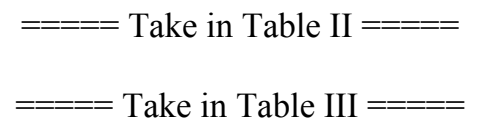

\section{Hypothesis testing}

Correlation and regression analyses were then employed to analyse the relationships between the five constructs of the theoretical framework focusing on testing the proposed hypotheses by undertaking three research tasks. Firstly, revealing whether KM constructs (KR, KA, KD and KU) are associated with the $\mathrm{BP}$ construct; and if they are, whether these associations are strong enough so that one or more KM construct(s) can be used to predict the variance of BP. Secondly, comparing the predicting power of different KM factors (KM1-KM9) on the variance of BP factors (PF, PC, PP and PL), and identifying the KM factors with comparatively larger predicting power. Finally, identifying the relationships (if any) between the four BP factors (representing the interactions among the four perspectives of the BSC). Meanwhile, through these analyses, the nomological validity of the scales of the five constructs and their associated factors was also tested (Peter, 1981).

\section{Correlation analyses}

As shown in Table IV, the correlation analysis revealed that the four KM constructs were positively associated with the BP construct at the 0.01 level, with values of the Pearson coefficient of correlation $(r)$ ranging from 0.358 to 0.494 . Table $\mathrm{V}$ presents the results of an additional correlation analysis between the BP factors (PF, PC, PP and PL) and the KM1-KM9 factors with the following key findings:

- $\quad \mathrm{KM} 7-$ 'tacit knowledge dissemination' was positively associated with the PF factor having a Pearson correlation $r$ of 0.257 , significant at the 0.01 level;

- $\mathrm{KM1-'response} \mathrm{to} \mathrm{clients'} \mathrm{needs',} \mathrm{KM2-'response} \mathrm{to} \mathrm{market} \mathrm{knowledge',} \mathrm{KM3-'business}$ knowledge acquisition', KM7-'tacit knowledge dissemination', KM8-'explicit knowledge dissemination', and KM9-'knowledge utilisation' - all were positively associated with the PC, PP and PL factors and statistically significant at the 0.01 level;

- $\quad \mathrm{KM} 4-$ 'market knowledge acquisition’ and KM5- 'financial knowledge acquisition’ were positively associated with the PP and PL factors, at the 0.01 and 0.05 level respectively; and 
- $\quad$ KM6- 'acquisition of knowledge through training' was positively and significantly associated with the PC and PL factors at the 0.05 level.

The above findings support hypothesis H2 (i.e. intensity of KM activities is positively associated with the level of business performance). In the meantime, the significant correlations between KM and BP constructs/factors upheld the nomological validity of their scales (Brown et al., 2005; Wang and Netemeyer, 2004).

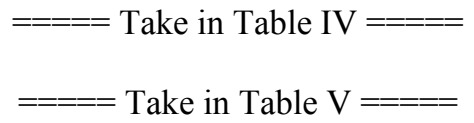

\section{Regression analyses}

In this study, stepwise multiple regression analysis was applied in order to: 1) predict and explain the variance of BP and those of its four factors individually; 2) determine the most influential KM constructs on BP; and 3) identify the most influential KM factors on the BP factors (Hair et al., 1998: 578). The 143 cases in the data file satisfied the minimum sample size required for carrying out the regression analysis (Tabachinick and Fidell, 2001:117). To pursue the stepwise analysis, a specific dependent variable (i.e. BP) was hypothesized as being influenced by a set of independent variables (i.e. KR, KA, KD and KU). The independent variables, which had strong correlation with a specific dependent variable, were entered step-by-step in its regression model. The final statistically significant model selected to predict this dependent variable had the smallest $\mathrm{S}^{2}$ (the mean square error) and the largest adjusted $\mathrm{R}^{2}$ (the multiple coefficient of determination).

As presented in Table VI, the intensity of KU 'knowledge utilisation' explained and predicted $23.7 \%$ of the variance of BP. Meanwhile, the regression models reported in Table VII show that the intensity of three KM factors, i.e. KM2 'response to market knowledge', KM7 'tacit knowledge dissemination' and KM9 'knowledge utilisation', had significant predicting power on the BP factors. KM9 'knowledge utilisation', in particular, appears to be the most influential factor predicting the variance of three BP factors (i.e. PC, PP and PL). The regression analyses therefore support hypothesis $\mathrm{H} 3$ which proposes that intensity of KM activities can be used to predict, and to explain, the level of business performance measured from different perspectives of the BSC. As the level of both PP and PL factors can be predicted 
and explained to a larger degree by select $\mathrm{KM}$ factors as indicated by the comparatively larger Adj. $\mathrm{R}^{2}$ values of their regression models, hypothesis H4 is also supported.

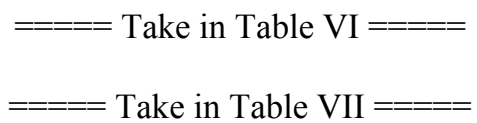

Regression analyses were also undertaken to identify the relationships among the BP factors (PF, PC, PP and PL). For example, a regression models illustrated in Table VIII demonstrates that the combined BP level measured from both 'financial' and 'business process' perspectives was found to predict and explain $45.1 \%$ of the variance of the BP level measured from the 'customer' perspective. Similar findings, listed in Table VIII, are in line with the causal relationships assumed to exist between the different BSC perspectives. These relationships are also graphically illustrated in Figure 2 which captures all the results of the regression analyses and highlights the influence of selected KM factors (i.e. KM2, KM7 and KM9) on the leading indicators of business performance, namely the PP and PL factors - both of which, in turn, are drivers of future financial performance.

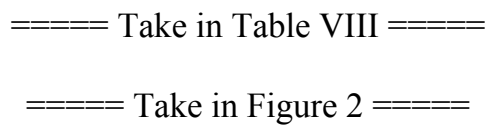

In summary, the quantitative study found strong empirical evidence that business performance is strongly and positively associated with the four different types of KM activities (i.e. responsive to knowledge, knowledge acquisition, dissemination and utilisation). In addition, specific KM activities, in particular, 'tacit knowledge dissemination' and 'knowledge utilisation' have stronger predicting power of the leading performance indicators, through which, such KM activities appear to indirectly influence the lagging performance indicators, such as 'financial performance'.

\section{Qualitative study and discussion}

Qualitative data acquired via the questionnaires and interviews revealed that many established common practices used by organisations to improve business performance and to realise business objectives were, in fact, various combinations of different categories of $\mathrm{KM}$ activities, although they were not literally articulated as 'KM activities' by practitioners; just as an interviewee indicated: “KM activities had always been, and should continue to be, an integral part of our processes and policies rather than practices independent of our business operations". Comments made regarding KM activities of perceived 
contribution to business performance are summarised hereinafter, under the headings of the four BSC perspectives, thus providing some support to the relationships identified from the statistical analyses.

\section{KM's contribution to performance from the financial perspective}

The qualitative study reflected the importance of sharing valuable tacit knowledge among staff, and the need for continuous improvement. Unfortunately, many interviewees were unable to clearly distinguish between KM and information management in the context of identifying KM's contribution to financial performance. In this context, interviewees identified the use of IT network systems as the common approach to increase the efficiency of managing projects, which indirectly improves financial performance. This is not surprising as no direct relationship between 'explicit knowledge dissemination' and the lagging indicator 'financial performance' could be empirically established, see Table V.

\section{KM's contribution to performance from the customer perspective}

All interviewees agreed that the main two drivers for KM are to enhance the value of their services and create more value to their clients. In addition, they asserted that activities for managing both tacit and explicit knowledge are crucial for responding to clients quickly, meeting client's expectations and securing future contracts. Examples of tacit KM activities include benchmarking quality and pricing of competitive products and setting relevant marketing strategies accordingly; and studying potential markets segments with reference to recently completed projects and mapping future trends and expectations. Activities of managing explicit knowledge, such as building a project information database was also perceived as particularly relevant to the sustainability of the business. Although these information management systems are not really KM systems, they nevertheless are critical to providing data in a timely manner. These qualitative findings provide some support to the positive and significant correlations found between various KM activities/factors (notably KU/KM9: knowledge utilisation) and business performance measured from the 'customer' perspective.

\section{KM's contribution to performance from the business process perspective}

Interviewees recognise that knowledge sharing is the key to improve the efficiency of their business processes. It was encouraging indeed to receive feedback indicating that various communication channels which facilitate tacit knowledge externalisation, dissemination and utilisation are perceived as the core contributor to improving business processes. Few respondents even provided good examples of knowledge sharing among staff. Regular corporate meetings, project progress reviews, and innovation 
task-force meetings, were commonly used to share experiences, to reflect on market needs particularly during the tendering process, to review existing internal business processes, and to discuss process redesign in order to improve overall efficiency. However, these examples were limited only to knowledge sharing rather than the creation of new knowledge. During the interviews, many opined that: "any KM system or programme should fit various existing internal business processes smoothly, and should enable the utilisation of newly acquired knowledge for process improvement". As such, this opinion is compatible with the empirical findings where most KM factors had positive correlations with the business performance measured from the 'process' perspective.

\section{KM's contribution to performance from the learning perspective}

Recent studies argue that KM activities contribute positively to organisational learning (Choy et al., 2006). Interviewees commented: "in this fast changing world of business, $\mathrm{KM}$ is essential to the professional development of our employees which, in turn, lead to long-term business enhancement". To facilitate the organisational learning process, organisations appear to have different mechanisms to encourage and motivate staff to share tacit knowledge. One of the most common mechanisms is sharing lessons learnt on recently completed projects to leverage collective organisational knowledge for usage in future projects. This usually takes the form of holding post-project review meetings where problems get identified and analysed in order to externalise and to disseminate knowledge among employees. In addition to regular professional seminars and workshops, many organisations seem to painstakingly collect and analyse productivity data, and make it accessible to staff for future use. This affirmed our empirical findings where both 'tacit knowledge dissemination' and 'knowledge utilisation' are found to be major predictors of the business performance measured from the 'learning' perspective.

\section{Concluding Remarks}

The study concludes that within the context of construction organisations managing organisational knowledge is of fundamental importance for business sustainability; KM strategies need to be explicitly formulated and measured according to overall organisational business objectives; and tacit knowledge dissemination and knowledge utilisation plays a paramount role of improving business performance.

Organisational growth comes from three principal sources: people, system, and organisational procedures, which constitute the infrastructure of an organisation, and require investment if the organisation is to achieve ambitious long-term financial growth objectives (Kaplan and Norton, 1996). The quantitative 
study established strong and positive associations between most of KM activities and the leading indicators of the BSC (i.e. PL 'performance from the learning perspective' and PP 'performance from process perspective'). Two specific types of KM activities (i.e. tacit knowledge dissemination and knowledge utilisation) in particular are of strong predicting power over the variance of PP and PL. This finding implies the potential positive contribution of these KM activities to the foundation on which the entire BSC house is build, and to the processes that must excel at in order to continue adding value for clients and ultimately, shareholders. In line with the BSC theory, this study also proved that the leading performance indicators are positively related to the lagging indicators (i.e. financial and market performance). These empirical findings were further augmented by views solicited from experienced practitioners, who stated that the intention of $\mathrm{KM}$ is to enhance the value of services and create more value to clients, which in turn helps to improve profitability.

The study also provides a valuable insight into the important role knowledge utilisation plays in the development of organisational knowledge asset. Knowledge utilisation appears to be the strongest predictor of business performance measured from any of the four BSC perspectives. This is compatible with the theoretical proposition which states that knowledge remains a hidden power until it gets applied (Hunt, 2003). Meanwhile, the theoretical argument about the importance of experience based and context specific tacit knowledge of the construction industry (Woo et al., 2004) is also reflected by the finding of this study. Tacit knowledge dissemination was empirically found with significant positive associations with every performance perspectives of the BSC, and also qualitatively revealed with a paramount role in improving performance.

The findings of this study suggest that for construction organisations, KM strategies should be formulated as an organic part of business strategy and measured according to organisational objectives, particularly those reflected by the leading indicators of the BSC. KM process should be programmed as an integral part of business process, whilst with KM related activities, objectives, measures specifically outlined. Tacit knowledge externalisation, capture, dissemination and utilisation should be the focus of KM process. IT systems, which have been focus on managing explicit knowledge of the construction context, should be developed with more functions of facilitating tacit knowledge management activities.

Constrained by the resource available, this study was limited in relatively small sample size representing only one type of construction organisations in a specific region, i.e. Hong Kong. To reach better 
generalisability future research would benefit from a larger sample size, as well as greater sample diversity in terms of size and category of organisations and cultural context as well. Further qualitative studies such as in-depth case studies would be also desired to detail the extent of KM activities' impact on business performance. Building upon the efforts of validating KM effectiveness, attention should also be paid to efficiency of KM, whilst such an investigation requires considerations of additional contextual constructs e.g. organisational culture and technological infrastructure. 


\section{References}

Alavi, M. and Leidner, D. E. (2001), "Review: Knowledge management and knowledge management systems: conceptual foundation and research issues", MIS Quarterly, Vol. 25 No. 1, pp. 107 134.

Andersen, H., Lawrie, G. and Shulver, M. (2000), "The Balanced Scorecard vs. the EFQM Business Excellence Model". 2GC Limited, UK, (available at http:/www.2gc.co.uk/pdf/2GCBSCvBEMp.pdf)

Andriessen, D. (2004), "Intellectual capital valuation and measurement: classifying the state of the art", Journal of Intellectual Capital, Vol. 5 No. 2, pp. 230-242.

Bassioni, Price and Hassan (2005), "Building a conceptual framework for measuring business performance in construction: an empirical evaluation", Construction Management \& Economics, Vol. 23 No. 5, pp. 495-507.

Bassioni, H. A., Price, A. D. F. and Hassan, T. M. (2004), "Performance measurement in construction", Journal of Management Engineering, Vol. 20 No. 2, pp. 42-50.

Brown, M. E., Trevino, L. K. and Harrison, D. A. (2005), "Ethical leadership: A social learning perspective for construct development and testing", Organizational Behavior and Human Decision Processes, Vol. 97 No. 2, pp. 117-134.

Byrne, B. M. (2001), Structual Equation Modeling with AMOS, Basic Concepts, Applications and Programming, Lawrence Erlbaum Associates, Publishers, London.

Cavaleri, S. A. (2004), "Leveraging organisational learning for knowledge and performance", The Learning Organisation, Vol. 11 No. 2, pp. 159-176.

Chen, L. and Mohamed, S. (2007), "Empirical study of interactions between knowledge management activities", Engineering, Construction and Architectural Management, Vol. 14 No. 3, pp. 242260 .

Chen, M. Y. and Chen, A. P. (2006), "Knowledge management performance evaluation: a decade review from 1995 to 2004", Journal of Information Science, Vol. 32 No. 1, pp. 17-38.

Choy, C. S., Yew, W. K. and Lin, B. (2006), "Criteria for measuring KM performance outcomes in organisations", Industrial Management \& Data System, Vol. 7 No. 106, pp. 917-936.

Coakes, S. J. (2005), SPSS: analysis without anguish: version 12.0 for Windows, John Wiley \& Son Australia, Ltd.

Darroch, J. (2003), "Developing a measure of knowledge management behaviours and practices", Journal of Knowledge Management, Vol. 7 No. 5, pp. 41-54.

Diakoulakis, I. E., Georgopoulos, N. B., Koulouriotis, D. E. and Emiris, D. M. (2004), "Towards a holistic knowledge management model", Journal of Knowledge Management, Vol. 8 No. 1, pp. $32-46$.

Droge, C., Claycomb, C. and Germain, R. (2003), "Does knowledge mediate the effect of context on performance? Some initial evidence", Decision Sciences, Vol. 34 No. 3, pp. 541-568.

Egbu, C., Anumba, C., Quintas, P., Hutchinson, V., Hayles, C. and Ruikar, K. (2003), "Techniques \& Technologies for Knowledge Management". (available at http://www.knowledgemanagement.uk.net)

ETWB (2005), "List of Approved Contractors for Public Works". The Environment, Transport and Works Bureau (ETWB) of the Government of the Hong Kong Special Administrative Region (HKSAR), (available at http://www.etwb.gov.hk/consultants_and_contractors/contractors) 
Gold, A. H., Malhotra, A. and Segars, A. H. (2001), "Knowledge management: an organizational capabilities perspective", Journal of Management Information System, Vol. 18 No. 1, pp. 185214.

Hair, J. F., Anderson, R. E., Tatham, R. L. and Black, W. C. (1998), Multivariate Data Analysis, PrenticeHall International, Inc., Upper Saddle River, N.J. .

Hari, S., Egbu, C. and Kumar, B. (2005), "A knowledge capture awareness tool: An empirical study on small and medium enterprises in the construction industry", Engineering, Construction and Architectural Management. , Vol. 12 No. 6, pp. 533-568.

HKCA (2005), "Hong Kong Construction Association Members List". Hong Kong Construction Association, (available at http://www.hkca.com.hk/new/pg_hkca_member.htm)

Hunt, D. P. (2003), "The concept of knowledge and how to measure it", Journal of Intellectual Capital, Vol. 4 No. 1, pp. 100-113.

Jashapara, A. (2003), "Cognition, culture and competition: an empirical test of the learning organisation", The Learning Organisation, Vol. 10 No. 1, pp. 31-50.

Kagioglou, M., Cooper, R. and Aouad, C. (2001), "Performance management in construction: a conceptual framework", Construction Management and Economics, Vol. 19 No. 1, pp. 85-95.

Kalling, T. (2003), "Knowledge management and the occasional links with performance", Journal of Knowledge Management, Vol. 7 No. 3, pp. 67-81.

Kaplan, R. S. and Norton, D. P. (1996), Translating Strategy into Action - The Balanced Scorecard, Harvard Business School Press, Boston.

Kululanga, G. K., McCaffer, R., Price, A. D. F. and Edum-Fotwe, F. (1999), "Learning mechanisms employed by construction contractors", Journal of Construction Engineering and Management, Vol. 125 No. 4, pp. 215-223.

Kululanga, G. K., Price, A. D. F. and McCaffer, R. (2002), "Empirical investigation of construction contractors' organizational learning", Journal of Construction Engineering and Management, Vol. 128 No. 5, pp. 385-391.

McCann, J. E. and Buckner, M. (2004), "Strategically integrating knowledge management initiatives", Journal of Knowledge Management, Vol. 8 No. 1, pp. 47-63.

Moffett, S., McAdam, R. and Parkinson, S. (2003), "An empirical analysis of knowledge management applications", Journal of Knowledge Management, Vol. 7 No. 3, pp. 6-26.

Mouritsen, J. (2004), "Measuring and intervening: how do we theorise intellectual capital management?" Journal of Intellectual Capital, Vol. 5 No. 2, pp. 257-267.

Nesan, L. J. (2004), "Efficacy-information for implementing learning in construction", The Learning Organisation, Vol. 11 No. 1, pp. 45-66.

Neuman, W. L. (2003), Social research methods: qualitative and quantitative approaches, Allyn and Bacon.

$\mathrm{Ng}$, K. H. (2003), "Application of knowledge management in Hong Kong construction industry", M.Sc. thesis, Department of Building and Construction, City University of Hong Kong.

Peter, J. P. (1981), "Construct validity: A review of basic issues and marketing practices", Journal of Marketing Research, Vol. 18 No. 2, pp. 133-145.

Robinson, H. S., Carrillo, P. M., Anumba, C. J. and Al-Ghassani, A. M. (2005), "Knowledge management practices in large construction organisations", Engineering, Construction and Architectural Management, Vol. 12 No. 5, pp. 431-445. 
Sveiby, K. E. (1997), The New Organisational Wealth: Managing and Measuring Knowledge-Based Assets, Berrett Koehler, San Francisco.

Tabachinick, B. G. and Fidell, L. S. (2001), Using Multivariate Statistics, Allyn and Bacon, Sydney.

Wang, G. and Netemeyer, R. G. (2004), "Salesperson creative performance: conceptualization, measurement, and nomological validity", Journal of Business Research, Vol. 57 No. 8, pp. 805812 .

Wongrassamee, S., Gardiner, P. D. and Simmons, J. E. L. (2003), "Performance measurement tools: the Balanced Scorecard and EFQM Excellence Model", Measuring Business Excellence, Vol. 7 No. 1, pp. 14-29.

Woo, J.-H., Clayton, M. J., Johnson, R. E., Flores, B. E. and Ellis, C. (2004), "Dynamic Knowledge Map: reusing experts' tacit knowledge in the AEC industry", Automation in Construction, Vol. 13 No. 2, pp. 203-207.

Yu, W. D. and Chang, P. L. (2005), "Performance evaluation of the construction knowledge management system - a case study of an A/E consulting firm", In the Proceedings of the International Conference on Construction Engineering and Management (ICCEM 2005): Globalization and Collaboration in Construction, Seoul, South Korea, pp. 1058-1063. 
Table I Demographical information of respondents

\begin{tabular}{|c|c|}
\hline Demographic Information of the respondents & Percentage \\
\hline \multicolumn{2}{|l|}{ Age } \\
\hline More than 40 years & $78.5 \%$ \\
\hline \multicolumn{2}{|l|}{ Educational background } \\
\hline A bachelor degree or higher & $82.6 \%$ \\
\hline \multicolumn{2}{|l|}{ Position } \\
\hline Top management & $40.6 \%$ \\
\hline Senior professional staff members & $59.3 \%$ \\
\hline \multicolumn{2}{|l|}{ Professional industry experience } \\
\hline More than 10 years & $91.3 \%$ \\
\hline \multicolumn{2}{|l|}{ Years working for the company } \\
\hline More than 5 Years & $75.8 \%$ \\
\hline \multicolumn{2}{|l|}{ Company categories } \\
\hline Local contractors & $62.6 \%$ \\
\hline Branches or subsidiary companies of overseas corporations & $21.8 \%$ \\
\hline Branches of state-owned enterprises of the People's Republic of China & $15.6 \%$ \\
\hline \multicolumn{2}{|l|}{ Company annual turnover } \\
\hline Less than HK $\$ 100$ million & $23.5 \%$ \\
\hline HK\$100-500 million & $22.8 \%$ \\
\hline HK\$ 501-1,000 million & $12.1 \%$ \\
\hline HK\$ $1,001-5,000$ million & $22.1 \%$ \\
\hline$>$ HK\$ 5000 million & $19.4 \%$ \\
\hline
\end{tabular}


Table II Factor analyses of KM constructs

\begin{tabular}{lc}
\hline \multicolumn{1}{c}{ KM constructs and factors } & Factor Loadings* \\
\hline Survey question: “Please indicate your opinions about the KM practices in your company. Our company...” & \\
Scale: $1=$ Strongly disagree, $2=$ Disagree, $3=$ Neither agree nor disagree, $4=$ Agree, 5 =Strongly agree & \\
\hline KR: Responsiveness to Knowledge (2 factors) & 0.866 \\
KM1: Response to clients' needs & 0.813 \\
\hline - responds quickly to any complaint raised by clients. & 0.785 \\
- promptly acts if clients are unsatisfied with the quality of service. & 0.748 \\
- makes a concerted effort to act on the clients' identified needs. & 0.839 \\
KM2: Response to market knowledge & 0.829 \\
- periodically reviews the likely effect of technological changes on clients. & 0.813 \\
- effectively implements marketing plans. & 0.761 \\
- $\quad$ endeavours to improve the cost effectiveness of marketing service. & 0.596 \\
\hline
\end{tabular}

KA: Knowledge Acquisition (4 factors)

KM3: Business knowledge acquisition

- undertakes structured and meaningful market research.

- surveys clients to assess the quality of our projects or services.

- holds regular meetings with employees to generate business ideas.

- undertakes staff appraisals to facilitate their input in our operations.

- frequently acquires new business ideas through working with others.

KM4: Market knowledge acquisition

- quickly detects changes in market needs (e.g. preference of clients).

- drives business direction according to the changes in market needs.

- actively and timely collects information about our competitors.

- occasionally meets with major clients to find out their future needs.

KM5: Financial knowledge acquisition

- analyses regularly the financial contribution of our projects or services.

- has good financial information about our business operations.

- knows how much each of our projects costs us.

KM6: Training based knowledge acquisition

- encourages employees to undertake formal university courses.

- encourages employees to attend training seminars and conferences.

\section{KD: Knowledge Dissemination (2 factors)}

KM7: Tacit knowledge dissemination

- encourages open communication.

- actively encourages staff mentoring or coaching.

- records internal best practices on a regular basis.

- frequently steps back and review all aspects of our business.

- market needs/ trends are frequently discussed by managerial and technical staff.

KM8: Explicit knowledge dissemination

- documents (e.g. reports and newsletters) about our business achievements are periodically circulated to external stakeholders.

- GroupWare (e.g., Lotus Notes) is frequently used to share information.

- policy and procedure manuals are frequently updated.

- written reports are circulated to disseminate knowledge.

\section{KU: Knowledge Utilisation (1 factor)}

KM9 Knowledge utilisation

- uses accumulated knowledge to solve new problems.

- is able to apply knowledge to changing competitive conditions.

- uses shared knowledge to improve efficiency.

- matches sources of knowledge to problems and challenges.

- applies knowledge learned from mistakes.

*Extraction Method: Principal Component Analysis. Rotation Method: Varimax with Kaiser Normalization; factor loadings: significant at the 0.05 and of a power level of $80 \%$.

Total Variance Explained (\%) of the four factor analyses: KR: 68.3\%, KA: 65.8\%, KD: $60.2 \%$, KU: 65.5\% 
Table III Factor analysis of BP construct

Factors and Measurement Variables

Factor Loadings*

Survey question: "To the best of your knowledge, please circle the number which you feel estimates how your company compare to the average level of immediate competitors (contractors) in Hong Kong on each item, within the past financial year."

Scale: 1 = much less, 2 = less, $3=$ same, $4=$ more, $5=$ much more

\section{BP: Business Performance (4 factors)}

PF: Performance from financial perspective

- average return on investment

- average profit

- turnover growth

PC: Performance from customer perspective

- ability to gain contracts

- market share

- level of client satisfaction

- ability to gain repeat business

- reputation to deliver quality services

PP: Performance from process perspective

- reduce construction time

- streamline internal processes

- increase working to schedule

- improve project quality

- rapidly commercialise new innovations

PL: Performance from learning perspective

- the morale

- employees' motivation to act in the best interest of the company

- the level of employee satisfaction

- employees' freedom to take to make decisions and take actions

- the productivity of employees

- the skill of employees

- ability of our existing information system to provide rapid, timely and accurate information about market and business operations

Notes:

Extraction method: Principal component analysis. Rotation method: Varimax with Kaiser normalisation; factor loadings: significant at the 0.05 and of a power level of $80 \%$.

Total Variance Explained (\%): 64.2\%. Reliability (Cronbach's Alpha) of BP scale: 0.906 
Table IV Pearson correlations between KM and BP constructs

\begin{tabular}{lcccc}
\hline Constructs & KR & KA & KD & KU \\
\hline BP: Business performance & $0.446^{* *}$ & $0.358^{* *}$ & $0.422^{* *}$ & $0.494 * *$ \\
\hline
\end{tabular}

Notes: **: Correlation is significant at the 0.01 level (2-tailed).

Table V Pearson correlations between KM and BP factors

\begin{tabular}{|c|c|c|c|c|}
\hline Constructs and factors & $\mathbf{P F}$ & PC & $\mathbf{P P}$ & PL \\
\hline \multicolumn{5}{|l|}{ Responsiveness to knowledge construct (KR): } \\
\hline KM1: Response to clients' needs & 0.046 & $0.275^{* *}$ & $0.342 * *$ & $0.299 * *$ \\
\hline KM2: Response to market knowledge & 0.084 & $0.314 * *$ & $0.518 * *$ & $0.494 * *$ \\
\hline \multicolumn{5}{|l|}{ Knowledge acquisition construct (KA): } \\
\hline KM3: Business knowledge acquisition & 0.156 & $0.231 * *$ & $0.368 * *$ & $0.416^{* *}$ \\
\hline KM4: Market knowledge acquisition & 0.007 & 0.144 & $0.445^{* *}$ & $0.231 * *$ \\
\hline KM5: Financial knowledge acquisition & 0.004 & 0.134 & $0.226^{*}$ & $0.268 * *$ \\
\hline KM6: Training based knowledge acquisition & 0.030 & $0.213^{*}$ & 0.163 & $0.186^{*}$ \\
\hline \multicolumn{5}{|l|}{ Knowledge dissemination construct (KD): } \\
\hline KM7: Tacit knowledge dissemination & $0.257 * *$ & $0.287 * *$ & $0.461 * *$ & $0.570 * *$ \\
\hline KM8: Explicit knowledge dissemination & 0.087 & $0.222 * *$ & $0.425 * *$ & $0.378 * *$ \\
\hline \multicolumn{5}{|l|}{ Knowledge utilisation construct (KU): } \\
\hline KM9: Knowledge utilisation & 0.065 & $0.314 * *$ & $0.568 * *$ & $0.537 * *$ \\
\hline
\end{tabular}

Notes: *: Correlation significant at the 0.05 level (2-tailed). **: Correlation significant at the 0.01 level (2-tailed)..

Table VI Regression model for KM and BP constructs

\begin{tabular}{|c|c|c|c|c|c|}
\hline \multirow{2}{*}{ Dependent Variables } & \multirow{2}{*}{$\begin{array}{c}\text { Independent Variables } \\
\text { Unstandardised Coefficients B/ } \\
\text { Standardised Coefficient } \beta \\
\text { (t statistic) }\end{array}$} & \multicolumn{4}{|c|}{ Model Summary } \\
\hline & & $\mathbf{R}$ & $\mathbf{R}^{2}$ & Adj. $\mathbf{R}^{2}$ & $\mathbf{F}$ \\
\hline $\begin{array}{l}\text { BP: Business } \\
\text { performance }\end{array}$ & $\begin{array}{c}1.584 / 0.494 \\
\left(5.876^{* * *}\right)\end{array}$ & 0.494 & 0.244 & 0.237 & $34.531 * * *$ \\
\hline
\end{tabular}

Notes: $* * *$ : significant at 0.0005 level. 
Table VII Regression models for KM and BP factors

\begin{tabular}{|c|c|c|c|c|c|c|c|}
\hline \multirow[t]{2}{*}{ Dependent Variables } & \multicolumn{3}{|c|}{$\begin{array}{c}\text { Unstandardised Coefficients B/ } \\
\text { Standardised Coefficient } \beta \\
\text { (t statistic) }\end{array}$} & \multicolumn{4}{|c|}{ Model Summary } \\
\hline & KM2 & KM7 & KM9 & $\mathbf{R}$ & $\mathbf{R}^{2}$ & Adj. $R^{2}$ & $\mathbf{F}$ \\
\hline $\begin{array}{l}\text { PF: Performance from } \\
\text { financial perspective }\end{array}$ & & $\begin{array}{c}0.288 / \\
0.257 \\
(2.942 *)\end{array}$ & & 0.257 & $0.066^{a}$ & 0.059 & $8.655^{*}$ \\
\hline $\begin{array}{l}\text { PC: Performance from } \\
\text { customer perspective }\end{array}$ & & & $\begin{array}{c}0.324 / \\
0.314 \\
(3.761 * *)\end{array}$ & 0.314 & 0.099 & 0.092 & $14.143 * *$ \\
\hline $\begin{array}{l}\text { PP: Performance from } \\
\text { process perspective }\end{array}$ & $\begin{array}{c}0.219 / \\
0.252 \\
(2.632 *)\end{array}$ & & $\begin{array}{c}0.377 / \\
0.401 \\
\left(4.183^{* *}\right)\end{array}$ & 0.598 & 0.358 & 0.347 & $34.816^{* *}$ \\
\hline $\begin{array}{l}\text { PL: Performance from } \\
\text { learning perspective }\end{array}$ & & $\begin{array}{c}0.523 / \\
0.382 \\
(4.104 * *) \\
\end{array}$ & $\begin{array}{c}0.345 / \\
0.284 \\
\left(3.055^{*}\right)\end{array}$ & 0.609 & 0.370 & 0.361 & $37.934 * *$ \\
\hline
\end{tabular}

Notes:

**: significant at 0.001 level. *: significant at 0.01 level.

a : insignificant at 0.05 level, without a power of 0.80 .

Table VIII Regression models for BP factors

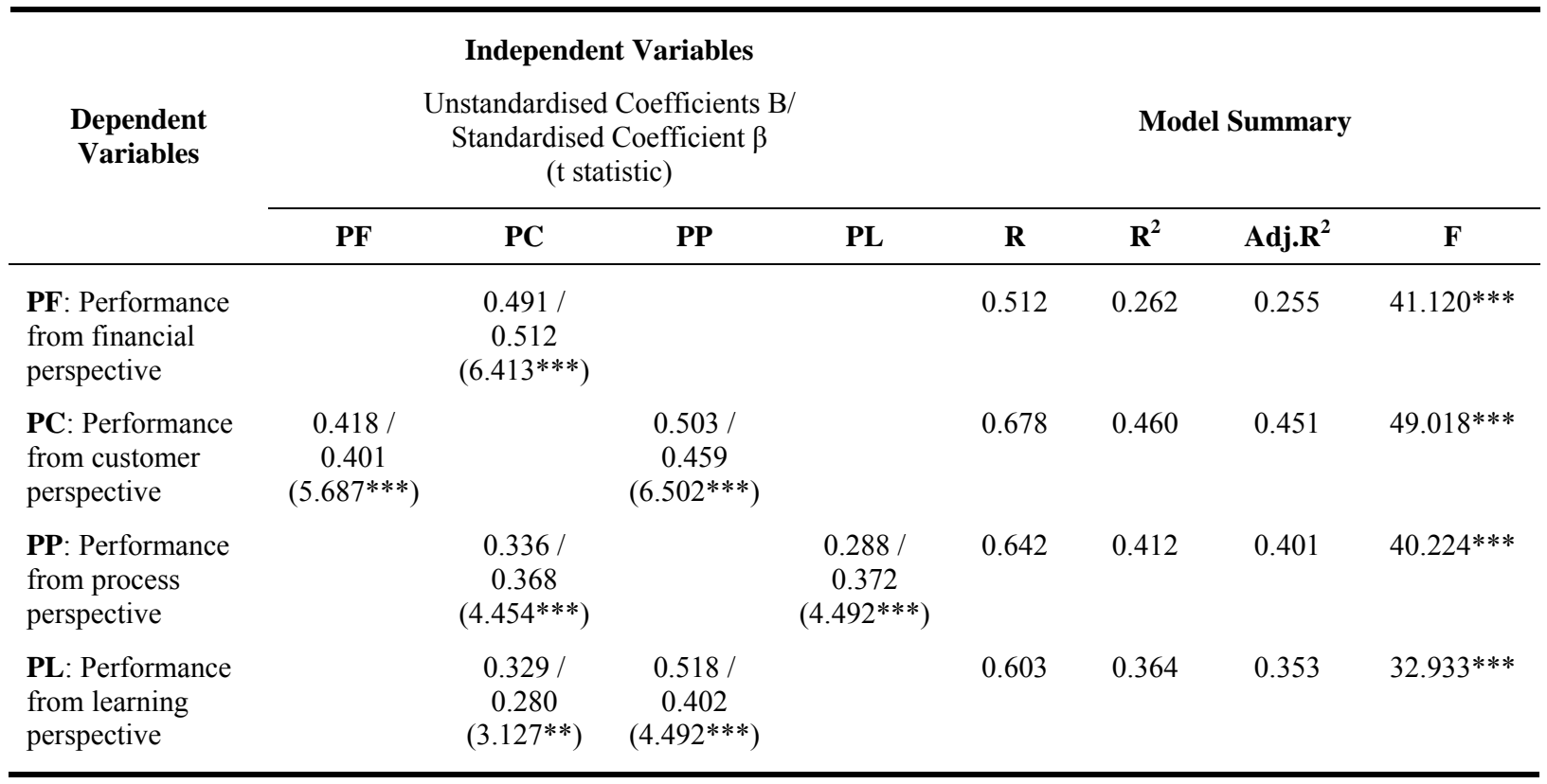

Notes: ***: significant at 0.0005 level. $* *$ : significant at 0.01 level. 


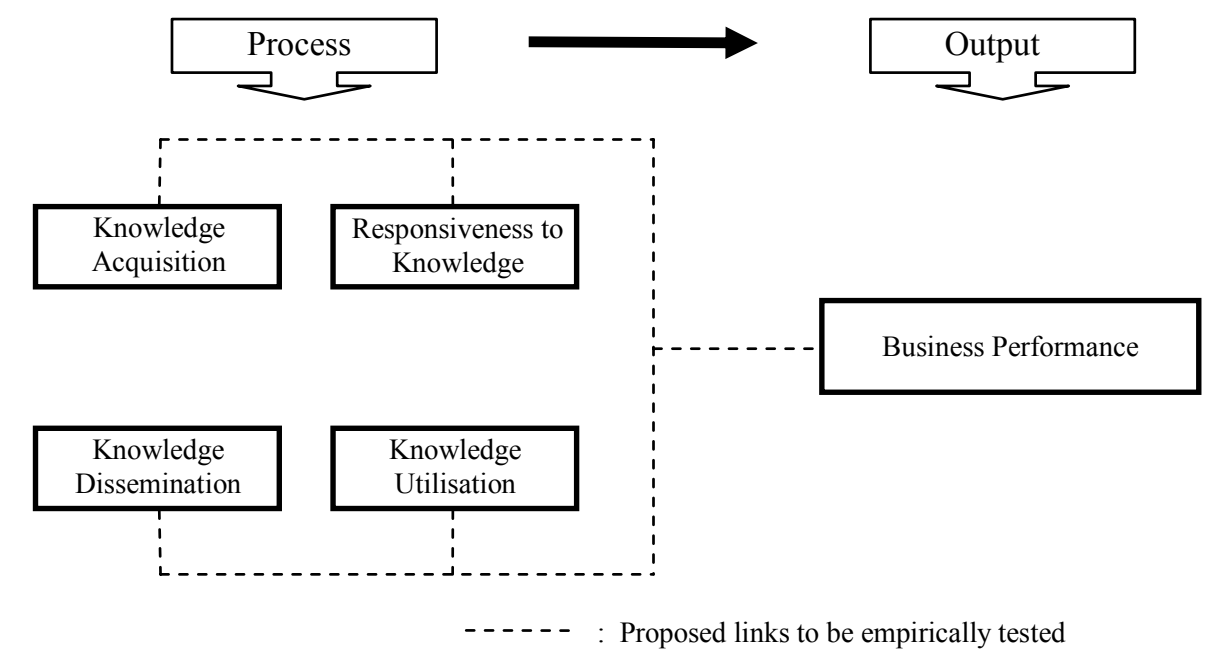

Figure 1 Theoretical framework of KM and BP 


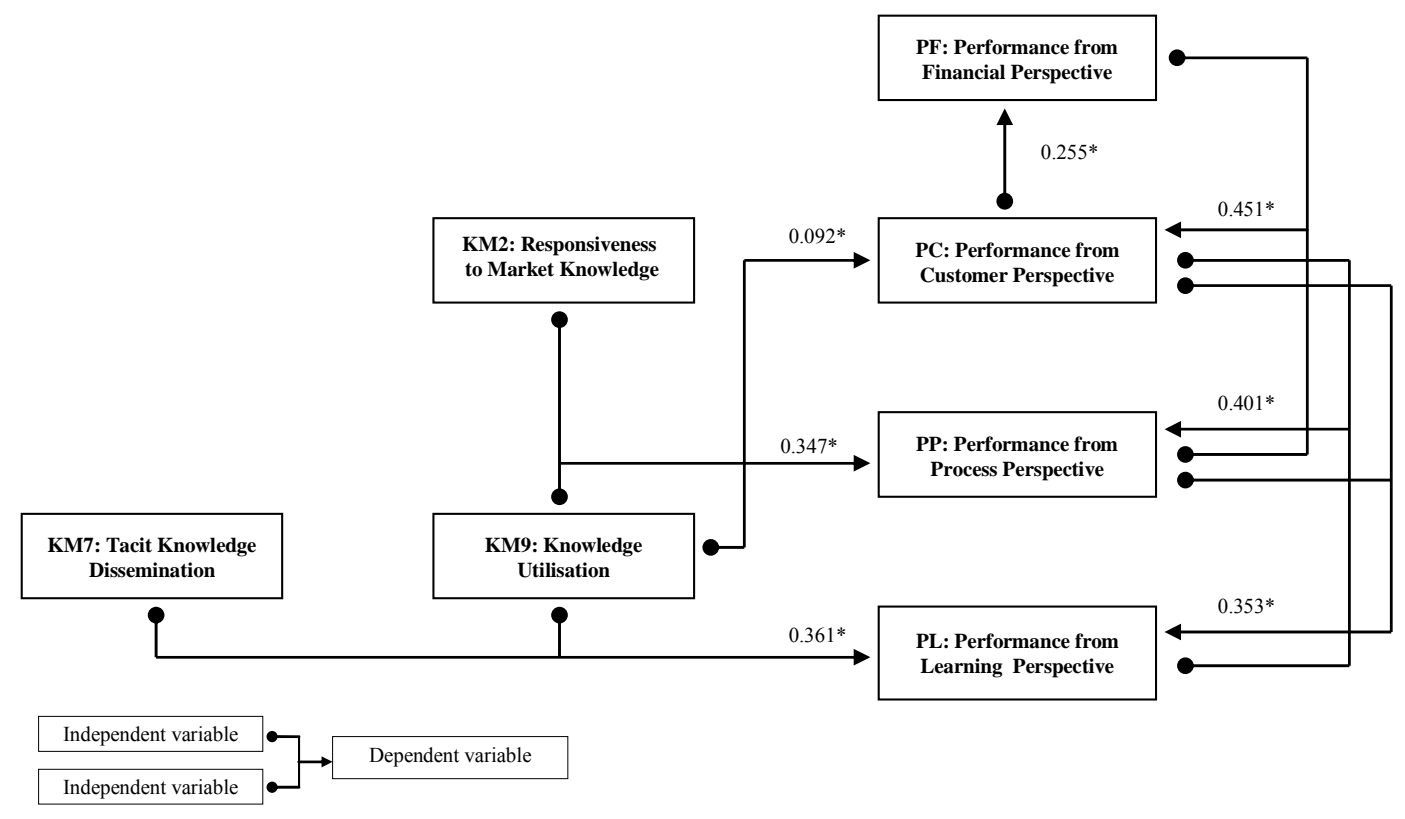

Note: *Adj. $\mathrm{R}^{2}$ : Adjusted coefficient of determination, with a power of 0.80 and significant at 0.05 level.

Figure 2 Regression analyses of KM and BP factors 